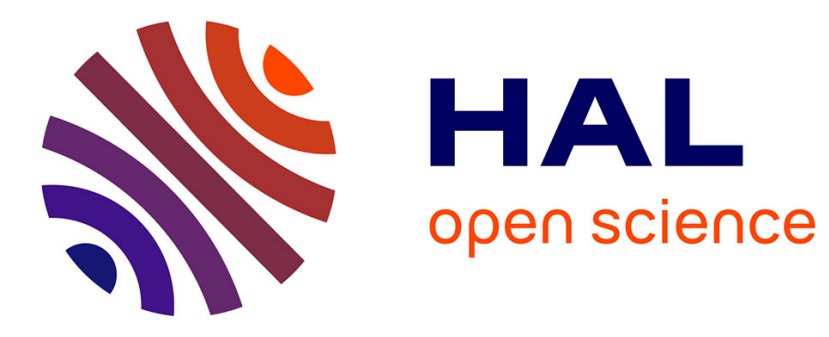

\title{
Remyelination in multiple sclerosis: from basic science to clinical translation
}

\author{
Catherine Lubetzki, Bernard Zalc, Anna Williams, Christine Stadelmann, \\ Bruno Stankoff
}

\section{- To cite this version:}

Catherine Lubetzki, Bernard Zalc, Anna Williams, Christine Stadelmann, Bruno Stankoff. Remyelination in multiple sclerosis: from basic science to clinical translation. The Lancet Neurology, 2020, 19 (8), pp.678-688. 10.1016/S1474-4422(20)30140-X . hal-03020152

\section{HAL Id: hal-03020152 https://hal.sorbonne-universite.fr/hal-03020152}

Submitted on 23 Nov 2020

HAL is a multi-disciplinary open access archive for the deposit and dissemination of scientific research documents, whether they are published or not. The documents may come from teaching and research institutions in France or abroad, or from public or private research centers.
L'archive ouverte pluridisciplinaire HAL, est destinée au dépôt et à la diffusion de documents scientifiques de niveau recherche, publiés ou non, émanant des établissements d'enseignement et de recherche français ou étrangers, des laboratoires publics ou privés. 


\section{Remyelination in multiple sclerosis: from basic science to clinical translation}

Catherine Lubetzki ${ }^{1,2}$ MD-PhD, Bernard Zalc ${ }^{1}$ MD-PhD, Anna Williams ${ }^{3}$ MB ChB$\mathrm{PhD}$, Christine Stadelmann ${ }^{4} \mathrm{MD}$, Bruno Stankoff ${ }^{1,5} \mathrm{MD}-\mathrm{PhD}$

1 Sorbonne University, Inserm, CNRS, ICM-Groupe hospitalier Pitié-Salpêtrière, Paris France

2 Assistance Publique des Hôpitaux de Paris (APHP), Neurology department, Groupe hospitalier Pitié-Salpêtrière, Paris, France

3 Centre for Regenerative Medicine, University of Edinburgh, BioQuarter, 5 Little France Drive, Edinburgh EH16 4UU, UK

4 Institute of Neuropathology, University Medical Center Göttingen, Göttingen, Germany

5 Assistance Publique des Hôpitaux de Paris (APHP), Neurology department, Hôpital Saint-Antoine, Paris, France

$\begin{array}{ll}\text { Catherine LUBETZKI } & \text { catherine.lubetzki@aphp.fr } \\ \text { Bernard ZALC } & \text { Bernard.zalc@upmc.fr } \\ \text { Anna WILLIAMS } & \text { anna.williams@ed.ac.uk } \\ \text { Christina STADELMANN } & \text { cstadelmann@med.uni-goettingen.de } \\ \text { Bruno STANKOFF } & \text { bruno.stankoff@aphp.fr }\end{array}$

Catherine Lubetzki reports grants and personal fees from BIOGEN, personal fees from MERCKSERONO, personal fees from ROCHE, personal fees from REWIND, personal fees from IPSEN, outside the submitted work. Bernard Zalc has nothing to disclose. Anna Williams has nothing to disclose. Christine Stadelmann reports grants and personal fees from NOVARTIS, personal fees from ROCHE, grants from MedDay, outside the submitted work. Bruno Stankoff reports grants and personal fees from ROCHE, SANOFI-GENZYME, and MERCK-SERONO, personal fees from NOVARTIS, BIOGEN and TEVA, outside the submitted work 
Contributions : Catherine Lubetzki defined initially the scope of the review. All authors contributed to writing and revising all aspects of the manuscrip

\section{Summary}

Multiple sclerosis treatment has been transformed by the successful development of immunotherapies, which efficiently reduce disease activity and related clinical relapses during the relapsing-remitting phase of the disease. However, preventing accumulation of disability progression, the consequence of axonal and neuronal damage and loss, remains a major unmet need and a therapeutic challenge in particular during the progressive phase of the disease. One strategy to counteract neurodegeneration is to promote neuroprotection by enhancing myelin regeneration, hence restoring nerve conduction and metabolic support to the axon. Preclinical research has provided targets to improve brain and spinal cord remyelination paving the way for translation to humans. From these initial promising forays, further problems have emerged, including how to best design these clinical trials, and appropriately measure outcomes. These need further work to translate efficacious pro-remyelination therapies to people with multiple sclerosis, but there is real hope now that we are on our way to success.

Multiple sclerosis (MS) is an inflammatory, demyelinating and neurodegenerative disease of the central nervous system (CNS), with a prevalence of 50-300 per 100000 persons. It is an important cause of acquired non-traumatic disability of the young adult. During the last two decades, the development of immunotherapies, acting on the inflammatory component of the disease has significantly reduced CNS lesion formation and relapse rate ${ }^{1}$. However, these therapies are insufficient to prevent accumulation of permanent disability, a consequence of axonal and neuronal damage and loss, particularly during the progressive phase of the disease ${ }^{2,3}$. This has led to a change of strategy by the field, focusing on ways to protect against neurodegeneration to avoid progressive disability in MS. This is, of course, a similar strategy to that for many other neurodegenerative diseases, such as motor neuron disease, stroke and Alzheimer's disease. However, in MS, as demyelination is pathognomonic, there exists the therapeutic option of restoring the myelin - remyelination (i.e., myelin regeneration) - 
which improves both nerve conduction velocity and metabolic support to the underlying axon. This confers an advantage to be used as a therapeutic test-bed for other neurodegenerative conditions where white matter abnormalities and demyelination have been identified ${ }^{4,5,6}$. Here, we will review how far we have come on this therapeutic journey to help progressive MS patients. We will describe evidence that myelin regeneration is useful as neuroprotection, how it occurs and is controlled and how we can translate this knowledge into strategies and clinical trials to enhance remyelination and neuroprotection in people with MS.

We have focused on relevant topics that are novel, but with good quality of evidence, emphasizing therapeutic compounds that have emerged from different screens and been confirmed in different models. For the therapeutic trials update, we selected ongoing or completed registered phase 2 studies targeting remyelination as described below. We searched PubMed for articles published in English, with the search terms "multiple sclerosis", "demyelination", "remyelination", "oligodendrocytes", "neurodegeneration", "neuroprotection", "clinical trial". We favored papers published after 2015, but not excluding previous seminal papers.

\section{1) What is myelin and how is it involved in MS?}

Myelin, a specific acquisition of vertebrates, consists of membrane spirally wrapped around large diameter axons, synthesized by oligodendrocytes (OL) in the CNS and Schwann cells in the PNS. Compared to other biological membranes, the biochemical constitution of myelin is unique with $70 \%$ lipids and $30 \%$ proteins, i.e., the opposite to other membranes. The myelin sheath is interrupted at intervals by nodes of Ranvier. While in non-myelinated fibres voltage dependent sodium channels ( $\mathrm{Nav}$ ) are evenly distributed along the axons causing the nerve influx to move continuously, in myelinated axons, $\mathrm{Na}_{v}$ are clustered at the node of Ranvier and the action potential 'jumps' from one node to the next. This mode of propagation known as saltatory conduction allows rapid transmission of the action potential along the axon (50- to 100fold acceleration compared to unmyelinated axons of similar diameter). Apart from its impact on conduction, OL also provide nutrition to the underlying axons, in particular in the form of lactate, fueling axonal mitochondria, which crucially supports the highly 
energy demanding axonal transport $7,8,9$. $\mathrm{K}+$ clearance through OL-specific $\mathrm{K}+$ channels, was also shown to be critical for axonal function and integrity ${ }^{10,11}$.

In MS, an adaptive immune response directed against CNS antigens, consisting of both $T$ and $B$ cells likely drives disease pathogenesis. The innate immune system is also involved in initiation and progression of MS (review $\mathrm{in}^{12}$ ), all leading to demyelination, axon and neuronal loss. In addition to an acute, inflammationdependent axonal pathology, several mechanisms contribute to neurodegeneration of long term demyelinated axons, in particular the redistribution of $\mathrm{Na}_{v}$ channels along the denuded axon ${ }^{13}$, the altered $\mathrm{K}+$ clearance due to oligodendroglial $\mathrm{K}+$ channels loss $^{14}$, and the loss of oligodendroglial nutritional support, which increases the energy demand of the denuded axon (review in ${ }^{2}$.) (figure 1).

\section{2) Does remyelination promote neuroprotection?}

Remyelination can occur in the CNS, restoring myelin sheaths to axons, aiding nerve conduction but also metabolic support. Several complementary lines of evidence demonstrate that remyelination can therefore confer neuroprotection.

\section{2-1) Evidence from human neuropathology and experimental studies}

In MS tissue, neuropathological studies have demonstrated that the density of axons is higher ${ }^{15}$ and markers of acute axonal damage (beta-amyloid-precursor protein$\beta$ APP- positive axons) are lower ${ }^{16}$ in remyelinated compared to demyelinated areas, suggesting that remyelination offers neuroprotection. However, in post mortem tissue, it is impossible to unpick whether remyelination has occurred because axons have remained healthy, or whether remyelination has actually resulted in axonal preservation. Experimentally (see Panel 1 on models and review in ${ }^{17}$ ), in mice where demyelination was induced by cuprizone, Irvine and Blakemore ${ }^{18}$ were among the first to demonstrate that remyelination can protect from axonal degeneration, where spontaneous repair was prevented by X-ray irradiation. Recently, using a genetic approach to accelerate remyelination by ablation of M1 muscarinic receptor, Mei et al. demonstrated that remyelination helps preserve axonal density and therefore 
presumably integrity in a mouse experimental auto-immune encephalomyelitis (EAE) model ${ }^{19}$. Furthermore, some experimental studies have demonstrated remyelinationinduced recovery of neurological deficits, such as in a cat model of demyelination ${ }^{20}$. Demyelination of grey matter is particularly abundant in progressive MS, and remyelination might therefore offer additional benefits to conductivity and network function ${ }^{21,22}$. It is unclear however whether remyelination provides the equivalent amount of neuroprotection to developmental myelin, bearing in mind that the myelin is thinner and shorter. After long term follow up in mice remyelinated after cuprizone treatment, there was axonal loss, suggesting that the neuroprotection may not be full, but with the caveat that cuprizone is also known to be toxic to axons ${ }^{23}$.

\section{2-2) Evidence from human imaging studies}

Whereas remyelination has been extensively described in experimental models, its natural history and extent remain only partly described in humans with MS due to difficulties in visualizing this in vivo. MRI is useful for MS diagnosis and follow up, but the sequences generally used in the clinical setting lack specificity towards myelin. The introduction of advanced quantitative sequences allows for more direct measures of remyelination in vivo. Magnetization transfer imaging (MTI) indicate the dynamics of demyelination and remyelination in MS lesions ${ }^{24}$. Interestingly, recovery of the MTI signal was not restricted to recent lesions, but was also observed in older pre-existing ones, supporting the notion that repeated bouts of demyelination and remyelination could take place in the same lesions along the disease course ${ }^{25}$. Furthermore, complementary MRI sequences based on diffusion weighted sequences or T2 relaxometry may also report myelin changes ${ }^{26,27}$. Although these MRI-based techniques hold great promise, they only reflect the physical properties of the brain, without direct molecular specificity.

Positron emission tomography (PET) offers the opportunity to develop a specific and sensitive technique to quantify myelin dynamics by using radiotracers that bind to myelin. Several stilbene and benzothiazole compounds, including the most recently developed fluorinated tracers ${ }^{18} \mathrm{~F}$-florbetapir and ${ }^{18} \mathrm{~F}$-florbetaben, have been shown to bind to CNS myelin ${ }^{28,29}$ and could be repurposed to quantify myelin loss and repair in vivo. A pilot study in subjects with relapsing-remitting MS using the benzothiazole 
derivative $\left[{ }^{11} \mathrm{C}\right]-\mathrm{PIB}$, confirmed the potential of PET to quantify myelin content in MS lesions and to capture demyelination and remyelination over time. Remyelination was detected within a 2 to 4 -month period and was found to be extremely heterogeneous between subjects and lesions. The level of remyelination strongly inversely correlated with disability scores, with subjects with better remyelination profiles having a preserved normalized thalamic volume compared to those with less remyelination ${ }^{30}$ (Fig.2), demonstrating its neuroprotective function in vivo. Whether the amount of remyelination is intrinsically different between individuals, or reflective of disease activity or stage is not yet known.

\section{3) Which cells carry out remyelination in the human CNS?}

There is currently debate as to which cells of the human adult CNS can and do carry out remyelination - oligodendrocyte precursor cells (OPCs), mature oligodendrocytes $(\mathrm{OL})$ or both. This is of importance as therapeutic strategies to enhance each route to achieve remyelination are likely to be different.

\section{3-1) Insight from experimental models}

In the CNS, developmental myelination is accomplished by OL derived from OPCs. During embryonic and early postnatal development, oligodendrocyte progenitors are generated from neural stem cells (NSC), then transit to the stage of OPCs, before differentiating into OL, which finally mature into myelin-forming OL. Each of these developmental stages is characterized by expression of specific markers ${ }^{31}$. In the adult, OPCs persist, accounting for 5 to $8 \%$ of all CNS cells. Experimental models have established using lineage tracing that after demyelination new myelin is synthesized by newly formed $\mathrm{OL}$ generated from OPCs ${ }^{32}$ which can be attracted to the lesion site by guidance cues, without the need for cell division ${ }^{33,34}$. In addition to OPCs, subventricular zone NSC present in the adult CNS can differentiate into OL. Recent studies have suggested that remyelination by progenitors from NSC produce myelin sheaths which are thicker and more functional than those derived from OPCs ${ }^{35,36}$. In addition, we now know that mature OL may participate in myelin regeneration, as suggested by studies from demyelinating models in cats and rhesus monkeys, where during clinical recovery mature OLs were seen by electron microscopy to have produced both thick and thin myelin sheaths on similar sized axons, suggestive of normal and remyelinated sheaths respectively ${ }^{37}$. These recent data are in line with the pioneering work of 
Gumpel showing that $\mathrm{OL}$ isolated from adult rat brain can remyelinate axons when grafted into newborn hypo-myelinated Shiverer mouse brain ${ }^{38}$.

\section{3-2) Insight from MS tissue}

Although the evidence that remyelination exists in animal models of demyelination is incontrovertible, identification in humans is more complex. Presumed remyelinated lesions in human post mortem brain are identified according to the presence of thinner myelin sheaths, which are distinguishable from normal appearing white matter on Luxol Fast Blue histological stains as paler "shadow" plaques (fig.3A).

Remyelinated areas may be complete ("shadow plaque") or positioned on the edge of a demyelinated lesion. These areas have been shown by electron microscopy to have thinner myelin sheaths ${ }^{39}$ and shorter internodal length ${ }^{40,41}$ (both characteristic of remyelinated lesions in animal models ${ }^{42,43}$ ). However, on a single post mortem human sample, it is difficult to prove definitively that shadow plaques result from a dynamic remyelination process, and areas of pale myelin staining may also represent areas where myelin is instead breaking down - so called "initial lesions"-. This appears unlikely, since, if there is active breakdown of myelin, an innate immune system response is expected, while in contrast few microglia/macrophages are generally found in remyelinated areas. One needs to be very meticulous at defining areas of remyelination, so not to confuse them with areas of edema, or even areas of grey matter, where there are fewer myelin sheaths. If we assume that we can extrapolate the characteristics of animal model remyelination to human, areas of established remyelination exist on pathological examination and reflecting the evidence from in vivo imaging, as described above ${ }^{44,30}$. In this context, cells expressing breast carcinoma amplified sequence 1 (BCAS1), a marker for a subpopulation of myelinating oligodendrocytes, were detected in post-mortem MS tissue ${ }^{45}$. Although rarely found in completely demyelinated lesions, clusters of $\mathrm{BCAS1}{ }^{+}$oligodendrocytes were detected at the lesion borders and in lesion areas characterized by pale myelin staining, providing further evidence that these areas indeed represent areas of remyelination (figure 3 B-D).

In chronic demyelinated white matter MS lesions, OPCs and newly formed myelinating OL have been identified using specific markers ${ }^{41,45}$ and an increased density of sub-ventricular zone progenitors (expressing the polysialylated form of 
neural cell adhesion molecule (PSA-NCAM)) has been reported in MS compared to control samples ${ }^{46}$, suggesting a precursor-led process, similar to that in development and in animal models of remyelination. However, new data using carbon dating of oligodendrocytes have suggested that myelin repair in the adult CNS might depend mostly on pre-existing oligodendrocytes. Testing of nuclear bombs released ${ }^{14} \mathrm{C}$ which is integrated into genomic DNA by dividing cells in concentrations matching those in the atmosphere, allowing inference of the age of cells and cell turnover by their ${ }^{14} \mathrm{C}$ content ${ }^{47}$. Using this technique on sorted nuclei from post mortem MS human brains (with CC1 and SOX10 antibodies to identify nuclei from mature OL and OPCs, respectively), there were some patients with aggressive MS where there was evidence of many newly formed oligodendrocytes. However, in most patients apparent 'shadow plaques' showed ${ }^{14} \mathrm{C}$ levels consistent with older cells (rather than newly generated ones), and no increase in the number of mature oligodendroglia or OPC proliferation, suggesting that pre-existing (older) OL (or OPCs that did not divide before maturing) may have formed the new myelin sheath ${ }^{48}$. The novel implication here is that pre-existing OL may be able to extend processes and form new myelin sheaths to remyelinate axons in MS. Some tentative further support for this comes from studies of heterogeneity of human oligodendroglia from single nuclei RNAsequencing from human post mortem brain. Here, fewer OPCs were found in MS brain compared to controls, and there were heterogeneous functional states of mature myelinating OL, including those producing many RNAs involved in the process of (re)myelination and others with more RNAs involved in signaling and presumed metabolic support ${ }^{49}$. Although it is not yet clear whether mature oligodendroglia can transition back and forth between states, the finding of functional heterogeneity would support this as a possibility. Therefore, we do not yet understand how much remyelination is secondary to newly formed $\mathrm{OL}$ from dividing OPCs or from pre-existing OL, how effective each route is and whether this changes with species, age or type of pathology, but the evidence points to the likelihood of at least some remyelination occurring through mature oligodendrocytes. This finding of two routes to remyelination is clearly of significance to the development of proremyelination therapies in the treatment of diseases such as MS, but currently all target the classical OPC route. 


\section{4) The "machinery" of myelin regeneration}

\section{4-1) Oligodendroglial biology of repair}

Our understanding of mechanisms involved in remyelination is mostly derived from experimental studies, in which demyelinating lesions are usually induced by a myelinotoxic agent (lysophosphatidylcholine or ethidium bromide) resulting in focal areas of demyelination, or more diffuse myelin alteration such as in the cuprizone model. Although of clear interest because they are closer to the human pathology, inflammatory models such as EAE are more complex, with less reproducibility in term of demyelination chronology, localization and extent of lesions, hence less suitable to analysis of the remyelination. For the classical route of remyelination, from OPCs, the process mostly recapitulates development, with OPC proliferation, increased motility ${ }^{50}$, migration/recruitment, maturation into $\mathrm{OL}$ and finally myelin wrapping. One prerequisite for successful remyelination is the presence of axons (at least without irreversible damage). The other is a sufficient number of remyelinating cells. Of note, demyelinated lesions in MS vary with regard to their oligodendroglial content, some lesions containing immature OL perhaps unable or not yet engaged in myelin formation, whereas others are virtually devoid of cells of the oligodendroglial lineage ${ }^{41,51}$. The steps needed for achieving successful remyelination may therefore differ depending on the lesion type. For each step, key molecular pathways have been identified: PDGF and FGF induce cell division ${ }^{52,53}$, several guidance cues shown to be re-expressed after demyelination influence OPC recruitment towards the lesion, Semaphorin $3 \mathrm{~F}$ being attractant ${ }^{33}$, in contrast to the repellent effect of Semaphorin $3 \mathrm{~A}$ and Netrin $1^{33,54}$. Major progress has also been made in the identification of cues and pathways favoring or inhibiting the OPC maturation process. Among the inhibitors of OPC maturation are the Notch signaling pathway ${ }^{55}$, Lingo- $1^{56}$, the Wnt pathway ${ }^{57,58}$, muscarinic receptor signaling ${ }^{59}$, hyaluronan ${ }^{60}$, chondroitin sulfate proteoglycan ${ }^{61}$, and fibrinogen ${ }^{62}$. The mechano-responsive ion channel PIEZO1 has been identified as an inhibitor of maturation, with potential role in age- related loss of function of OPC ${ }^{63}$. In contrast, activation of the retinoid $X$ receptor $\gamma$ on OPCs favors oligodendroglial maturation ${ }^{64}$, as well as thyroid hormone ${ }^{65}$ and Vitamin $D^{66}$. Optimal expression of different miRNAs regulate the oligodendroglial maturation process ${ }^{67}$. Recent results have highlighted the role of the cytoskeleton in OL maturation, through RhoGTPase 
$\operatorname{Vav} 3^{68}$. From this very active research field, and with the caveat that these different steps of remyelination might differ between experimental models and MS, several therapeutic targets have emerged, paving the way to translation.

\section{4-2) Role of neuronal activity in myelination and remyelination}

The role of neuronal activity in myelination was shown by adding neurotoxins either blocking or stimulating electrical activity in myelinating CNS neuron-glial co-cultures, confirmed in vivo in the optic nerve after silencing electrical activity by intra-vitreal injection of tetrodotoxin ${ }^{69}$, then later corroborated for peripheral nervous system myelination ${ }^{70}$. More than 10 years later, optogenetics has allowed this question to be revisited showing that stimulation of neuronal activity promotes myelination in the mammalian brain ${ }^{71}$ and demonstrating that electrically active axons are preferentially myelinated ${ }^{72,73}$. Although it has been shown in different neuronal populations and in different species ${ }^{72,74}$, the mechanisms supporting the influence of neuronal activity on myelination remain only partially understood. There is no evidence that this effect is mediated through axo-glial synapses between axons and $\mathrm{OPC}^{75}$, although these may have an indirect role by favoring maturation of cells along the oligodendroglial lineage. Alternatively, the electrical activity-related effect on myelination may be mediated through vesicular glutamate release ${ }^{76}$ along axons, activating signaling pathways involved in local translation of the myelin gene MBP ${ }^{77}$. Such adaptive myelination has been hypothesized to be involved in experience-associated CNS plasticity (see review in ${ }^{78}$ ). In addition, the role of electrical activity has also been demonstrated in different experimental models of remyelination ${ }^{79,80}$, and this has paved the way for designing translational studies in humans aimed at stimulating electrical activity to foster remyelination (see below). In line with these results is the demonstration that exercise increases remyelination rate following toxin-induced demyelination in mice ${ }^{81}$, a result which might possibly bring new insight into the known influence of physical activity on wellbeing in MS.

It is not trivial to reconcile that electrically active axons are preferentially myelinated, but only axons are myelinated (and not dendrites or other cell processes) ${ }^{82}$ and that proper myelin sheaths can also be formed around non-electrically active synthetic fibers of the size of axons ${ }^{83}$. One explanation, suggested by ffrench-Constant ${ }^{84}$ is that there may be two programs of myelination: an intrinsic myelination program, where 
myelination is dictated by physical cues and an adaptive program, in which myelin sheaths are modified by electrical activity.

\section{4-3) Immune cells, the newcomers in remyelination}

Several studies have suggested that both the adaptive and innate immune systems influence myelination and remyelination. For adaptive immunity, mice lacking CD4+ or CD8+ $T$ cells remyelinate to a much lesser extent than in normal mice ${ }^{85}$, regulatory $T$ cells enhance CNS remyelination ${ }^{86}$ and Th17 lymphocytes inhibit remyelination ${ }^{87}$. Grafting lymphocytes from different MS patients into murine CNS demyelinated lesions influence remyelination, with inter-individual heterogeneity ${ }^{88}$. For innate immunity, microglia and blood-derived macrophages are present in the inflamed CNS, which can be distinguished in rodent models, but with more difficulty in the human damaged CNS ${ }^{89,90}$. Microglia are highly heterogeneous with a continuous spectrum of activation states ${ }^{91,92}$. They are often implicated in neural cell damage ${ }^{93}$, and in this context it was recently suggested that the envelope protein Env of a human endogenous retrovirus HERV might drive microglial-mediated axonal damage ${ }^{94}$. In contrast, studies have suggested that microglia/macrophages can have a regenerative function, and in particular can promote remyelination ${ }^{95,96}$. This regenerative impact is partly related to their capacity to clear myelin debris, crucial for myelin wrapping. Aging slows remyelination, which may be in part due to decreased phagocytic ability, which can be rejuvenated by innate immune cells from young animals delivered by parabiosis ${ }^{97}$. Efficient remyelination requires death of pro-inflammatory microglia followed by repopulation to a pro-regenerative state ${ }^{98}$, where they can secrete regenerative factors (including galectin 3 , activin $\mathrm{A}$, LIF, TNF $\alpha$ ) promoting OPC recruitment and differentiation $88,99,100,101,102$. In MS, activated microglia can be detected even in the normal-appearing white matter, whereas in active and slowly expanding lesions a drastic reduction of the homeostatic microglial marker P2RY12 has been reported ${ }^{89}$. Pre-clinical and clinical studies have suggested that the pro-remyelinating potency of some compounds might actually be acting by targeting (directly or indirectly) microglia ${ }^{103,104 .}$

Our better understanding of the machinery of myelin regeneration has led to discovery of target pathways to manipulate to improve it.

\section{5) Progress to remyelinating strategies in MS}




\section{5-1) Identification of potential pro-remyelinating candidates}

Initial screening strategies have been used to discover potential pro-remyelination candidate therapies via in vitro assays amenable to high-throughput of compounds and combinatorial chemistry. During the last 10 years, there have been several screens of bioactive small molecules on expression of myelin markers by primary rat optic nerve derived OPCs ${ }^{105}$ or mouse pluripotent epiblast stem-cell-derived OPCs ${ }^{106}$. These methods do not discriminate between drugs enhancing OPC proliferation and differentiation of OPC into OL or whether these differentiated $O L$ can form myelin sheaths. To test the latter is more complex, needing use of myelinating $\mathrm{OL} /$ neuron cocultures, for example using transgenic lines in which reporter expression is driven by a regulatory sequence turned on only in myelinating $\mathrm{OL}^{107}$, or perhaps using the binary indicant for myelination using micropillar arrays ${ }^{108}$. To validate these hits in remyelination, the most commonly used animal model is rodent EAE or the use of toxin-induced demyelination (see panel 1 on the experimental models). Despite their advantages these rodent models are not suitable to screen large numbers of compounds, but are rather a semi-final in vivo test of a handful of candidate molecules pre-selected by in vitro screening. Intermediate animal models have been developed: a novel screening platform for identifying potential remyelination-promoting compounds has been developed using zebrafish larvae ${ }^{109}$. A Xenopus laevis transgenic line has also been developed allowing conditional ablation of myelinating oligodendrocytes. After completion of demyelination, spontaneous remyelination occurs, and can be accelerated by adding drugs to the swimming water. This model constitutes a robust medium-throughput screening platform for myelin regeneration therapeutics ${ }^{110}$.

These experimental strategies have led to the identification of promising lead compounds to enhance remyelination, both repurposed and new compounds, targeting diverse pathways. This includes modulators of sphingosine-1-phosphate, muscarinic $M 1$, histamine $H 3$, retinoid $X$ receptor $\gamma$ or opioid kappa receptors; inhibitors of gammasecretase/Notch or leukotriene pathways; modulators of hormone signaling (androgens, estrogens, T3-T4); antipsychotics (quetiapine); antifungal (miconazole); steroids (clobetasol). Some of these compounds were shown to enhance $\mathrm{OL}$ maturation independently of their canonical targets, by enhancing the production of 8,9 
unsaturated sterols, suggesting a unifying signaling mechanism for OL maturation enhancers ${ }^{111}$. This was shown for instance for muscarinic antagonists (clemastine, benztropine), selective estrogen modulators (tamoxifen, bazedoxifene) or antifungal drugs (miconazole) ${ }^{112}$, but not for thyroid hormones or retinoid $X$ receptor $\gamma$ modulators that target transcription factors. Finally, it was recently demonstrated that fasting mimetic metformin can restore age-related impaired differentiation capacity of OPC ${ }^{113}$.

Overall, despite the very large number of identified promyelinating drugs only a few have been applied to date in phase 2 clinical trials.

\section{5-2) Update on clinical trials targeting myelin regeneration in MS}

We interrogated two clinical trials registers: "Clinical trial.gov" and "EU clinical trial register" excluding phase 1 studies and studies for which the last posted information dated more than 4 years ago, with no publication since. Text search terms were "remyelination" "repair" "multiple sclerosis", "optic neuritis". We selected trials in which remyelination/repair evaluation was either a primary or secondary outcome and excluded studies in which outcomes related to remyelination were part of exploratory or post-hoc analysis. Trials targeting neuroprotection directly (phenytoin, amiloride, ACTH, Sprint MS (ibudilast), MS SMART (multi-arm evaluating fluoxetine, amiloride, riluzole), biotin) were not included.

As shown in table 1, most trials enrolled patients with optic neuritis, with a few including patients with relapsing MS. Focusing on the optic nerve to assess repair is attractive as it allows i) an evaluation of remyelination through the quantification of latency of visual evoked potentials (VEP) (a reduced latency being indicative of remyelination) and ii) a quantitative assessment of retinal neuronal loss using optical coherence tomography (OCT). In addition, optic neuritis is a frequent symptom of MS often occurring during the early phase of the disease. It is not known, however, whether findings in the optic nerve extrapolate to other CNS areas or patients with MS. The few completed trials on patients with RMS (MS with relapses, with either a relapsingremitting or a progressive phenotype) have not demonstrated clinical impact (clinical outcome was the primary outcome in one single study evaluating opicinumab, NCT01864148) ${ }^{114}$. As for imaging outcomes, a small but significant MTR increase (which might correspond to remyelination) has been reported in two studies (GNbAC1, 
NCT02782858 and GSK239512, NCT01772199)115,116. In addition, GNbAC1-treated RRMS patients showed a reduced number of black holes and reduced brain atrophy ${ }^{115}$. Among the trials including patients with optic neuritis, only two have been completed so far, and have included patients with acute (opicinumab, NCT01721161) and chronic (clemastine, NCT02040298) optic neuritis (this latter trial with a cross-over design). These two trials ${ }^{117,118}$ showed some positive results, with reduced latency of the VEP, although only significant in the per-protocol population (and not in the intention to treat population) in the opicinumab study. Even if a solid conclusion from these trials is premature, these very recent results are exciting for MS therapeutic development, aimed at reducing disability progression, the major unmet need in MS treatments.

\section{Conclusions and Future Directions}

Recently, great progress has been made in understanding the biological mechanisms regulating remyelination success or failure and for the identification of candidate molecules promoting such repair. This is leading to novel strategies to promote remyelination in MS, in addition to targeting the auto-immune component of the disease. Already, in addition to electrophysiological devices, over 50 compounds have been identified as potent candidates for pro-remyelination trials, including repurposing of approved drugs. However, we are facing novel challenges to best design and optimally evaluate clinical trials for remyelination. Beyond classical short-term parallel arms studies, cross-over trials may indicate the sustainability of repair following drug withdrawal. However, this may result in very complex trials when several drugs, or dose-efficacy responses are analyzed. As heterogeneous endogenous remyelination profiles have been described among patients with MS and outcomes reflecting repair might be influenced by individual-related fluctuations, pre-therapeutical run-in periods preceding placebo-controlled phases could also help to capture the real pharmacological effect of tested drugs. Finally, for the optimal strategy for pivotal phase III trials, adaptive designs might be employed to offer flexible methods allowing preplanned changes after interim analysis ${ }^{119}$. However, such studies need sensitive outcomes than can be assessed in a short time frame for interim analysis. Further challenges include: i) which tools should be applied for remyelination assessment (neurovisual outcomes? Imaging tools covering the whole brain? Blood biomarkers?); 
ii) which MS patients should be included in trials (relapsing remitting or progressive? With still ongoing inflammatory demyelination or stable under highly efficient diseasemodifying therapy? With already efficient endogenous remyelination capacities or a global repair failure? With minor disability in order to prevent disability worsening or with high disability in order to promote recovery?); iii) which clinical metrics should be assessed to reflect remyelination and predict subsequent disability worsening? This latter point will be of crucial importance once a compound reaches the pivotal phase III stage and may be a candidate for regulatory approval. Global disability scales such as EDSS represent consensual outcomes, but more focused reproducible metrics such as walking, processing speed and hand function, reflecting highly myelinated networks, might also be considered as primary outcomes. Whether a remyelinating strategy should improve preexisting disability (a strategy that implies viable demyelinated axons still permissive to repair) or prevent subsequent disability worsening (which would attest of the neuroprotective role of myelin regeneration) also remain key unanswered questions. Overall, there is a need for strong methodological research that will combine and test these complementary options as secondary or exploratory objectives to allow us to choose the most powerful study designs that will best detect repair success. Otherwise, we risk dismissing drugs that actually work by simply measuring the wrong outcomes in the wrong patients. However, that the field has reached this stage is success itself and should provide hope for people with MS and their physicians.

Acknowledgements :

France: We thank ARSEP foundation, FRM (Fondation pour la Recherche Médicale), Bouvet-Labruyere Family, INSERM-DHOS, APHP (Assistance Publique des Hôpitaux de Paris), the program "Investissements d'Avenir" ANR-10-IAIHU-06, NeurATRIS, ANR grant BRECOMY to B.Z. and NRJ foundation for their precious support related to basic and clinical research on remyelination in Paris. UK: We thank the MS Society UK, MRC Regenerative Medicine Platform and the UK Dementia Research Initiative. Germany : CS was supported by the Deutsche Forschungsgemeinschaft (DFG) transregional collaborative research centers (CRC) 43 "The brain as a target of inflammatory processes" and 274 "Checkpoints of CNS recovery", STA 1389/5-1, the DFG under Germany's Excellence Strategy (EXC 2067/1- 390729940), the Gemeinnützige Hertie Foundation, the Deutsche Multiple Sklerose Gesellschaft (DMSG), and the National MS Society (USA). 


\section{Figure legends}

Figure 1 : Schematic representation of the different steps leading to disability progression in MS, as well as proposed strategies to prevent neurodegeneration.

Figure 2 : Individual remyelination profiles measured in vivo with a combination of MRI and $\left[{ }^{11} \mathrm{C}\right]$ PIB-PET associated with thalamic atrophy (courtesy of Matteo Tonietto and Benedetta Bodini). An illustrative MS patient shown in A and $\mathbf{B}$ has been evaluated with a combination of $\mathrm{MRI}$ and $\left[{ }^{11} \mathrm{C}\right]$ PIB-PET at study entry (A) and after 4 months (B). White matter lesions detected by MRI are displayed in white. Regions of demyelination detected by PET within lesions at study entry (A) are coloured in red. From the longitudinal follow up, individual indices of dynamic demyelination (not shown) and individual indices of dynamic remyelination were calculated; (B) areas in blue indicate voxels that were demyelinated at study entry and recovered normal myelin content at month 4 . As described ${ }^{26}$ from a pilot cohort of 19 patients with a relapsing form of MS, patients with a high remyelination index were classified as "good remyelinators" $(n=9)$, whereas patients with a low remyelination index were classified as "bad remyelinators" $(n=10)$. (C) Thalami were segmented and their normalized volumes calculated. (D) Good remyelinators showed less thalamic atrophy compared to bad remyelinators.

Figure 3 : BCAS1+ oligodendrocytes map areas of active remyelination in chronic multiple sclerosis. (A) Luxol fast blue/periodic-acid Schiff (LFB/PAS) histochemistry and (B, C, D) BCAS1 immunohistochemistry of subcortical white matter containing a chronic demyelinated lesion with an area of active remyelination (aRM). (C) Area of active remyelination depicted at higher magnification. (D) BCAS1+ oligodendrocyte in the demyelinated lesion, close to the edge of the area of active remyelination. Arrowheads indicate $\mathrm{BCAS1}^{+}$cells.

Figure 4 : schematic representation of the mechanisms/pathways involved in recruitment and maturation of oligodendrocyte precursor cells

OPC : oligodendrocyte precursor cell; OL : oligodendrocyte; Sema 3A/3F : semaphorin 3A/3F; CSPG : chondroitin sulfate proteoglycan; Vav2 : Rho GTPase regulating guanine nucleotide exchange factor; M1R : M1 muscarinic receptor; RXR $\gamma$ : retinoid $\mathrm{X}$ receptor gamma; NAWM : normal appearing white matter 
Table 1 : Trials (phase 2) targeting remyelination RR-MS : relapsing-remitting MS; RMS : MS with relapses (either relapsing-remitting or progressive disease); ON : optic neuritis: VEP : visual evoked potentials; RNFL : retinal nerve fiber layer; MTR : magnetization transfer ratio; PP : per-protocol population; ITT : intention to treat population; MOA : mechanism of action; Mab : monoclonal antibody

\section{References:}

1 Thompson AJ, Baranzini SE, Geurts J, Hemmer B, Ciccarelli O. Multiple sclerosis. Lancet 2018; 391: 1622-36.

2 Friese MA, Schattling B, Fugger L. Mechanisms of neurodegeneration and axonal dysfunction in multiple sclerosis. Nat Rev Neurol 2014; 10: 225-38.

3 Singh S, Dallenga T, Winkler A, et al. Relationship of acute axonal damage, Wallerian degeneration, and clinical disability in multiple sclerosis. J Neuroinflammation 2017; 14: 57.

4 Nasrabady SE, Rizvi B, Goldman JE, Brickman AM. White matter changes in Alzheimer's disease: a focus on myelin and oligodendrocytes. Acta Neuropathol Commun 2018; 6: 22.

5 Caso F, agosta F, Filippi M. Insights into White Matter Damage in Alzheimer's Disease: From Postmortem to in vivo Diffusion Tensor MRI Studies. Neurodegenerative Diseases 2016; 16: $26-$ 33.

6 Rajani RM, Quick S, Ruigrok SR, et al. Reversal of endothelial dysfunction reduces white matter vulnerability in cerebral small vessel disease in rats. Sci Transl Med 2018; 10.

DOI:10.1126/scitransImed.aam9507.

7 Fünfschilling U, Supplie LM, Mahad D, et al. Glycolytic oligodendrocytes maintain myelin and long-term axonal integrity. Nature 2012; 485: 517-21.

8 Saab AS, Nave K-A. Myelin dynamics: protecting and shaping neuronal functions. Curr Opin Neurobiol 2017; 47: 104-12.

9 Lee $\mathrm{Y}$, Morrison BM, Li Y, et al. Oligodendroglia metabolically support axons and contribute to neurodegeneration. Nature 2012; 487: 443-8.

10 Schirmer L, Möbius W, Zhao C, et al. Oligodendrocyte-encoded Kir4.1 function is required for axonal integrity. elife 2018; 7: e36428.

11 Larson VA, Mironova Y, Vanderpool KG, et al. Oligodendrocytes control potassium accumulation in white matter and seizure susceptibility. Elife 2018; 7. DOI:10.7554/eLife.34829.

12 Dendrou CA, Fugger L, Friese MA. Immunopathology of multiple sclerosis. Nat Rev Immunol 2015; 15: 545-58. 
13 Waxman SG, Craner MJ, Black JA. Na+ channel expression along axons in multiple sclerosis and its models. Trends Pharmacol Sci 2004; 25: 584-91.

14 Schirmer L, Srivastava R, Kalluri SR, et al. Differential loss of KIR4.1 immunoreactivity in multiple sclerosis lesions. Ann Neurol 2014; 75: 810-28.

15 Schultz V, van der Meer F, Wrzos C, et al. Acutely damaged axons are remyelinated in multiple sclerosis and experimental models of demyelination. Glia 2017; 65: 1350-60.

16 Kornek B, Storch MK, Weissert R, et al. Multiple sclerosis and chronic autoimmune encephalomyelitis: a comparative quantitative study of axonal injury in active, inactive, and remyelinated lesions. Am J Pathol 2000; 157: 267-76.

17 Lassmann H, Bradl M. Multiple sclerosis: experimental models and reality. Acta Neuropathol 2017; 133: 223-44.

18 Irvine KA, Blakemore WF. Remyelination protects axons from demyelination-associated axon degeneration. Brain 2008; 131: 1464-77.

19 Mei F, Lehmann-Horn K, Shen Y-AA, et al. Accelerated remyelination during inflammatory demyelination prevents axonal loss and improves functional recovery. Elife 2016; 5. DOI:10.7554/eLife.18246.

20 Duncan ID, Brower A, Kondo Y, Curlee JF, Schultz RD. Extensive remyelination of the CNS leads to functional recovery. Proc Natl Acad Sci USA 2009; 106: 6832-6.

21 Chang A, Staugaitis SM, Dutta R, et al. Cortical remyelination: a new target for repair therapies in multiple sclerosis. Ann Neurol 2012; 72: 918-26.

22 Battefeld A, Klooster J, Kole MHP. Myelinating satellite oligodendrocytes are integrated in a glial syncytium constraining neuronal high-frequency activity. Nat Commun 2016; 7: 11298.

23 Manrique-Hoyos N, Jürgens T, Grønborg M, et al. Late motor decline after accomplished remyelination: impact for progressive multiple sclerosis. Ann Neurol 2012; 71: 227-44.

24 Chen JT, Collins DL, Atkins HL, Freedman MS, Arnold DL, Canadian MS/BMT Study Group. Magnetization transfer ratio evolution with demyelination and remyelination in multiple sclerosis lesions. Ann Neurol 2008; 63: 254-62.

25 Brown RA, Narayanan S, Arnold DL. Imaging of repeated episodes of demyelination and remyelination in multiple sclerosis. Neuroimage Clin 2014; 6: 20-5.

26 Petiet A, Adanyeguh I, Aigrot M-S, et al. Ultrahigh field imaging of myelin disease models: Toward specific markers of myelin integrity? J Comp Neurol 2019; 527: 2179-89.

27 Fujiyoshi K, Hikishima K, Nakahara J, et al. Application of q-Space Diffusion MRI for the Visualization of White Matter. J Neurosci 2016; 36: 2796-808.

28 Stankoff B, Freeman L, Aigrot M-S, et al. Imaging central nervous system myelin by positron emission tomography in multiple sclerosis using [methyl- $\left.{ }^{11} \mathrm{C}\right]-2-\left(4^{\prime}\right.$-methylaminophenyl)- 6hydroxybenzothiazole. Ann Neurol 2011; 69: 673-80. 
29 Wu C, Zhu J, Baeslack J, et al. Longitudinal positron emission tomography imaging for monitoring myelin repair in the spinal cord. Ann Neurol 2013; 74: 688-98.

30 Bodini B, Veronese M, García-Lorenzo D, et al. Dynamic Imaging of Individual Remyelination Profiles in Multiple Sclerosis. Ann Neurol 2016; 79: 726-38.

31 Franklin RJM, Ffrench-Constant C. Regenerating CNS myelin - from mechanisms to experimental medicines. Nat Rev Neurosci 2017; 18: 753-69.

32 Zawadzka M, Rivers LE, Fancy SPJ, et al. CNS-resident glial progenitor/stem cells produce Schwann cells as well as oligodendrocytes during repair of CNS demyelination. Cell Stem Cell 2010; 6: 578-90.

33 Piaton G, Aigrot M-S, Williams A, et al. Class 3 semaphorins influence oligodendrocyte precursor recruitment and remyelination in adult central nervous system. Brain 2011; 134: 1156-67.

34 Boyd A, Zhang H, Williams A. Insufficient OPC migration into demyelinated lesions is a cause of poor remyelination in MS and mouse models. Acta Neuropathol 2013; 125: 841-59.

35 Xing YL, Röth PT, Stratton JAS, et al. Adult neural precursor cells from the subventricular zone contribute significantly to oligodendrocyte regeneration and remyelination. J Neurosci 2014; 34: 14128-46.

36 Remaud S, Ortiz FC, Perret-Jeanneret M, et al. Transient hypothyroidism favors oligodendrocyte generation providing functional remyelination in the adult mouse brain. Elife 2017; 6 .

DOI:10.7554/eLife.29996.

37 Duncan ID, Radcliff AB, Heidari M, Kidd G, August BK, Wierenga LA. The adult oligodendrocyte can participate in remyelination. Proc Natl Acad Sci USA 2018; 115: E11807-16.

38 Lubetzki C, Gansmüller A, Lachapelle F, Lombrail P, Gumpel M. Myelination by oligodendrocytes isolated from 4-6-week-old rat central nervous system and transplanted into newborn shiverer brain. J Neurol Sci 1988; 88: 161-75.

39 Périer O, Grégoire A. Electron microscopic features of multiple sclerosis lesions. Brain 1965; 88: 937-52.

40 Prineas JW, Connell F. Remyelination in multiple sclerosis. Ann Neurol 1979; 5: 22-31.

41 Chang A, Tourtellotte WW, Rudick R, Trapp BD. Premyelinating oligodendrocytes in chronic lesions of multiple sclerosis. N Engl J Med 2002; 346: 165-73.

42 Bunge $\mathrm{MB}$, Bunge RP, Ris $\mathrm{H}$. Ultrastructural study of remyelination in an experimental lesion in adult cat spinal cord. J Biophys Biochem Cytol 1961; 10: 67-94.

43 Blakemore WF. Pattern of remyelination in the CNS. Nature 1974; 249: 577-8.

44 Schmierer K, Scaravilli F, Altmann DR, Barker GJ, Miller DH. Magnetization transfer ratio and myelin in postmortem multiple sclerosis brain. Ann Neurol 2004; 56: 407-15.

45 Fard MK, van der Meer F, Sánchez P, et al. BCAS1 expression defines a population of early myelinating oligodendrocytes in multiple sclerosis lesions. Sci Trans/ Med 2017; 9. DOI:10.1126/scitransImed.aam7816. 
46 Nait-Oumesmar B, Picard-Riera N, Kerninon C, et al. Activation of the subventricular zone in multiple sclerosis: evidence for early glial progenitors. Proc Natl Acad Sci USA 2007; 104: 4694-9.

47 Yeung MSY, Zdunek S, Bergmann O, et al. Dynamics of oligodendrocyte generation and myelination in the human brain. Cell 2014; 159: 766-74.

48 Yeung MSY, Djelloul M, Steiner E, et al. Dynamics of oligodendrocyte generation in multiple sclerosis. Nature 2019; 566: 538-42.

49 Jäkel S, Agirre E, Mendanha Falcão A, et al. Altered human oligodendrocyte heterogeneity in multiple sclerosis. Nature 2019; 566: 543-7.

50 Moyon S, Dubessy AL, Aigrot MS, et al. Demyelination causes adult CNS progenitors to revert to an immature state and express immune cues that support their migration. J Neurosci 2015; 35 : 4-20.

51 Stangel M, Kuhlmann T, Matthews PM, Kilpatrick TJ. Achievements and obstacles of remyelinating therapies in multiple sclerosis. Nat Rev Neurol 2017; 13: 742-54.

52 Woodruff RH, Fruttiger M, Richardson WD, Franklin RJM. Platelet-derived growth factor regulates oligodendrocyte progenitor numbers in adult CNS and their response following CNS demyelination. Mol Cell Neurosci 2004; 25: 252-62.

53 Wang $\mathrm{Z}$, Colognato $\mathrm{H}$, Ffrench-Constant $\mathrm{C}$. Contrasting effects of mitogenic growth factors on myelination in neuron-oligodendrocyte co-cultures. Glia 2007; 55: 537-45.

54 Tepavčević $\mathrm{V}$, Kerninon C, Aigrot MS, et al. Early netrin-1 expression impairs central nervous system remyelination. Ann Neurol 2014; 76: 252-68.

55 Mathieu PA, Almeira Gubiani MF, Rodríguez D, Gómez Pinto LI, Calcagno M de L, Adamo AM. Demyelination-Remyelination in the Central Nervous System: Ligand-Dependent Participation of the Notch Signaling Pathway. Toxicol Sci 2019; published online June 6.

DOI:10.1093/toxsci/kfz130.

56 Mi S, Miller RH, Lee X, et al. LINGO-1 negatively regulates myelination by oligodendrocytes. Nat Neurosci 2005; 8: 745-51.

57 Fancy SPJ, Baranzini SE, Zhao C, et al. Dysregulation of the Wnt pathway inhibits timely myelination and remyelination in the mammalian CNS. Genes Dev 2009; 23: 1571-85.

58 Dai Z-M, Sun S, Wang C, et al. Stage-specific regulation of oligodendrocyte development by Wnt/ $\beta$-catenin signaling. J Neurosci 2014; 34: 8467-73.

59 Mei F, Fancy SPJ, Shen Y-AA, et al. Micropillar arrays as a high-throughput screening platform for therapeutics in multiple sclerosis. Nat Med 2014; 20: 954-60.

60 Back SA, Tuohy TMF, Chen $\mathrm{H}$, et al. Hyaluronan accumulates in demyelinated lesions and inhibits oligodendrocyte progenitor maturation. Nat Med 2005; 11: 966-72.

61 Pu A, Stephenson EL, Yong VW. The extracellular matrix: Focus on oligodendrocyte biology and targeting CSPGs for remyelination therapies. Glia 2018; 66: 1809-25. 
62 Petersen MA, Ryu JK, Chang K-J, et al. Fibrinogen Activates BMP Signaling in Oligodendrocyte Progenitor Cells and Inhibits Remyelination after Vascular Damage. Neuron 2017; 96: $1003-$ 1012.e7.

63 Segel M, Neumann B, Hill MFE, et al. Niche stiffness underlies the ageing of central nervous system progenitor cells. Nature 2019; 573: 130-4.

64 Huang JK, Jarjour AA, Nait Oumesmar B, et al. Retinoid X receptor gamma signaling accelerates CNS remyelination. Nat Neurosci 2011; 14: 45-53.

65 Hartley MD, Banerji T, Tagge IJ, et al. Myelin repair stimulated by CNS-selective thyroid hormone action. JCl Insight 2019; 4. DOI:10.1172/jci.insight.126329.

66 de la Fuente AG, Errea O, van Wijngaarden $P$, et al. Vitamin D receptor-retinoid X receptor heterodimer signaling regulates oligodendrocyte progenitor cell differentiation. J Cell Biol 2015; 211: $975-85$.

67 Emery B, Lu QR. Transcriptional and Epigenetic Regulation of Oligodendrocyte Development and Myelination in the Central Nervous System. Cold Spring Harb Perspect Biol 2015; 7: a020461.

68 Ulc A, Zeug A, Bauch J, et al. The guanine nucleotide exchange factor Vav3 modulates oligodendrocyte precursor differentiation and supports remyelination in white matter lesions. Glia 2019; 67: 376-92.

69 Demerens $C$, Stankoff B, Logak M, et al. Induction of myelination in the central nervous system by electrical activity. Proc Natl Acad Sci USA 1996; 93: 9887-92.

70 Stevens B, Tanner S, Fields RD. Control of myelination by specific patterns of neural impulses. $J$ Neurosci 1998; 18: 9303-11.

71 Gibson EM, Purger D, Mount CW, et al. Neuronal activity promotes oligodendrogenesis and adaptive myelination in the mammalian brain. Science 2014; 344: 1252304.

72 Koudelka S, Voas MG, Almeida RG, et al. Individual Neuronal Subtypes Exhibit Diversity in CNS Myelination Mediated by Synaptic Vesicle Release. Curr Biol 2016; 26: 1447-55.

73 Mitew S, Gobius I, Fenlon LR, et al. Pharmacogenetic stimulation of neuronal activity increases myelination in an axon-specific manner. Nat Commun 2018; 9: 306.

74 Stedehouder J, Brizee D, Shpak G, Kushner SA. Activity-Dependent Myelination of Parvalbumin Interneurons Mediated by Axonal Morphological Plasticity. J Neurosci 2018; 38: 3631-42.

75 Bergles DE, Roberts JD, Somogyi P, Jahr CE. Glutamatergic synapses on oligodendrocyte precursor cells in the hippocampus. Nature 2000; 405: 187-91.

76 Wake H, Ortiz FC, Woo DH, Lee PR, Angulo MC, Fields RD. Nonsynaptic junctions on myelinating glia promote preferential myelination of electrically active axons. Nat Commun 2015; 6: 7844.

77 Wake H, Lee PR, Fields RD. Control of Local Protein Synthesis and Initial Events in Myelination by Action Potentials. Science 2011; 333: 1647-51.

78 Fields RD. A new mechanism of nervous system plasticity: activity-dependent myelination. Nat Rev Neurosci 2015; 16: 756-67. 
79 Gautier HOB, Evans KA, Volbracht K, et al. Neuronal activity regulates remyelination via glutamate signalling to oligodendrocyte progenitors. Nat Commun 2015; 6: 8518.

80 Ortiz FC, Habermacher C, Graciarena M, et al. Neuronal activity in vivo enhances functional myelin repair. JCl Insight 2019; 5. DOI:10.1172/jci.insight.123434.

81 Jensen SK, Michaels NJ, llyntskyy S, Keough MB, Kovalchuk O, Yong VW. Multimodal Enhancement of Remyelination by Exercise with a Pivotal Role for Oligodendroglial PGC1 $\alpha$. Cell Rep 2018; 24: 3167-79.

82 Lubetzki C, Demerens C, Anglade P, et al. Even in culture, oligodendrocytes myelinate solely axons. Proc Natl Acad Sci USA 1993; 90: 6820-4.

83 Bechler ME, Byrne L, ffrench-Constant C. CNS Myelin Sheath Lengths Are an Intrinsic Property of Oligodendrocytes. Current Biology 2015; 25: 2411-6.

84 Bechler ME, Swire M, Ffrench-Constant C. Intrinsic and adaptive myelination-A sequential mechanism for smart wiring in the brain. Dev Neurobiol 2018; 78: 68-79.

85 Bieber AJ, Kerr S, Rodriguez M. Efficient central nervous system remyelination requires T cells. Ann Neurol 2003; 53: 680-4.

86 Dombrowski Y, O'Hagan T, Dittmer M, et al. Regulatory T cells promote myelin regeneration in the central nervous system. Nat Neurosci 2017; 20: 674-80.

87 Baxi EG, DeBruin J, Tosi DM, et al. Transfer of myelin-reactive th17 cells impairs endogenous remyelination in the central nervous system of cuprizone-fed mice. J Neurosci 2015; 35: 862639.

88 El Behi M, Sanson C, Bachelin C, et al. Adaptive human immunity drives remyelination in a mouse model of demyelination. Brain 2017; 140: 967-80.

89 Zrzavy T, Hametner S, Wimmer I, Butovsky O, Weiner HL, Lassmann H. Loss of 'homeostatic' microglia and patterns of their activation in active multiple sclerosis. Brain 2017; 140: 1900-13.

90 Peferoen LAN, Vogel DYS, Ummenthum K, et al. Activation status of human microglia is dependent on lesion formation stage and remyelination in multiple sclerosis. J Neuropathol Exp Neurol 2015; 74: 48-63.

91 Ransohoff RM. A polarizing question: do M1 and M2 microglia exist? Nat Neurosci 2016; 19: 987-91.

92 Stratoulias V, Venero JL, Tremblay M, Joseph B. Microglial subtypes: diversity within the microglial community. EMBO J 2019; 38. DOI:10.15252/embj.2019101997.

93 Masuda T, Sankowski R, Staszewski O, et al. Spatial and temporal heterogeneity of mouse and human microglia at single-cell resolution. Nature 2019; 566: 388-92.

94 Kremer D, Gruchot J, Weyers V, et al. pHERV-W envelope protein fuels microglial cell-dependent damage of myelinated axons in multiple sclerosis. Proc Natl Acad Sci USA 2019; 116: 15216-25. 
95 Kotter MR, Setzu A, Sim FJ, Van Rooijen N, Franklin RJ. Macrophage depletion impairs oligodendrocyte remyelination following lysolecithin-induced demyelination. Glia 2001; 35: 20412.

96 Lloyd AF, Miron VE. The pro-remyelination properties of microglia in the central nervous system. Nat Rev Neurol 2019; 15: 447-58.

97 Ruckh JM, Zhao J-W, Shadrach JL, et al. Rejuvenation of regeneration in the aging central nervous system. Cell Stem Cell 2012; 10: 96-103.

98 Lloyd AF, Davies CL, Holloway RK, et al. Central nervous system regeneration is driven by microglia necroptosis and repopulation. Nat Neurosci 2019; 22: 1046-52.

99 Miron VE. Microglia-driven regulation of oligodendrocyte lineage cells, myelination, and remyelination. J Leukoc Biol 2017; 101: 1103-8.

100 Miron VE, Boyd A, Zhao J-W, et al. M2 microglia/macrophages drive oligodendrocyte differentiation during CNS remyelination. Nat Neurosci 2013; 16: 1211-8.

101 Arnett HA, Mason J, Marino M, Suzuki K, Matsushima GK, Ting JP. TNF alpha promotes proliferation of oligodendrocyte progenitors and remyelination. Nat Neurosci 2001; 4: 1116-22.

102 Cunha MI, Su M, Cantuti-Castelvetri L, et al. Pro-inflammatory activation following demyelination is required for myelin clearance and oligodendrogenesis. J Exp Med 2020; 217. DOI:10.1084/jem.20191390.

103 Nörenberg W, Hempel C, Urban N, Sobottka H, Illes P, Schaefer M. Clemastine potentiates the human P2X7 receptor by sensitizing it to lower ATP concentrations. J Biol Chem 2011; 286: 11067-81.

104 Wang H, Liu S, Tian Y, et al. Quetiapine Inhibits Microglial Activation by Neutralizing Abnormal STIM1-Mediated Intercellular Calcium Homeostasis and Promotes Myelin Repair in a CuprizoneInduced Mouse Model of Demyelination. Front Cell Neurosci 2015; 9: 492.

105 Deshmukh VA, Tardif V, Lyssiotis CA, et al. A regenerative approach to the treatment of multiple sclerosis. Nature 2013; 502: 327-32.

106 Najm FJ, Madhavan M, Zaremba A, et al. Drug-based modulation of endogenous stem cells promotes functional remyelination in vivo. Nature 2015; 522: 216-20.

107 Stankoff B, Aigrot M-S, Noël F, Wattilliaux A, Zalc B, Lubetzki C. Ciliary neurotrophic factor (CNTF) enhances myelin formation: a novel role for CNTF and CNTF-related molecules. J Neurosci 2002; 22: 9221-7.

108 Mei F, Fancy SPJ, Shen Y-AA, et al. Micropillar arrays as a high-throughput screening platform for therapeutics in multiple sclerosis. Nat Med 2014; 20: 954-60.

109 Buckley CE, Marguerie A, Roach AG, et al. Drug reprofiling using zebrafish identifies novel compounds with potential pro-myelination effects. Neuropharmacology 2010; 59: 149-59.

110 Mannioui A, Vauzanges Q, Fini JB, et al. The Xenopus tadpole: An in vivo model to screen drugs favoring remyelination. Mult Scler 2018; 24: 1421-32. 
111 Hubler Z, Allimuthu D, Bederman I, et al. Accumulation of 8,9-unsaturated sterols drives oligodendrocyte formation and remyelination. Nature 2018; 560: 372-6.

112 Rankin KA, Mei F, Kim K, et al. Selective Estrogen Receptor Modulators Enhance CNS Remyelination Independent of Estrogen Receptors. J Neurosci 2019; 39: 2184-94.

113 Neumann B, Baror R, Zhao C, et al. Metformin Restores CNS Remyelination Capacity by Rejuvenating Aged Stem Cells. Cell Stem Cell 2019; 25: 473-485.e8.

114 Cadavid D, Mellion M, Hupperts R, et al. Safety and efficacy of opicinumab in patients with relapsing multiple sclerosis (SYNERGY): a randomised, placebo-controlled, phase 2 trial. Lancet Neurol 2019; 18: 845-56.

115 Diebold M, Derfuss T. The monoclonal antibody GNbAC1: targeting human endogenous retroviruses in multiple sclerosis. Ther Adv Neurol Disord 2019; 12: 1756286419833574.

116 Schwartzbach CJ, Grove RA, Brown R, Tompson D, Then Bergh F, Arnold DL. Lesion remyelinating activity of GSK239512 versus placebo in patients with relapsing-remitting multiple sclerosis: a randomised, single-blind, phase II study. J Neurol 2017; 264: 304-15.

117 Cadavid D, Balcer L, Galetta S, et al. Safety and efficacy of opicinumab in acute optic neuritis (RENEW): a randomised, placebo-controlled, phase 2 trial. Lancet Neurol 2017; 16: 189-99.

118 Green AJ, Gelfand JM, Cree BA, et al. Clemastine fumarate as a remyelinating therapy for multiple sclerosis (ReBUILD): a randomised, controlled, double-blind, crossover trial. Lancet 2017; 390: 2481-9.

119 Zhang Y, Salter A, Wallström E, Cutter G, Stüve O. Evolution of clinical trials in multiple sclerosis. Ther Adv Neurol Disord 2019; 12: 1756286419826547. 
(1) inflammation (2) Acute tissue damage

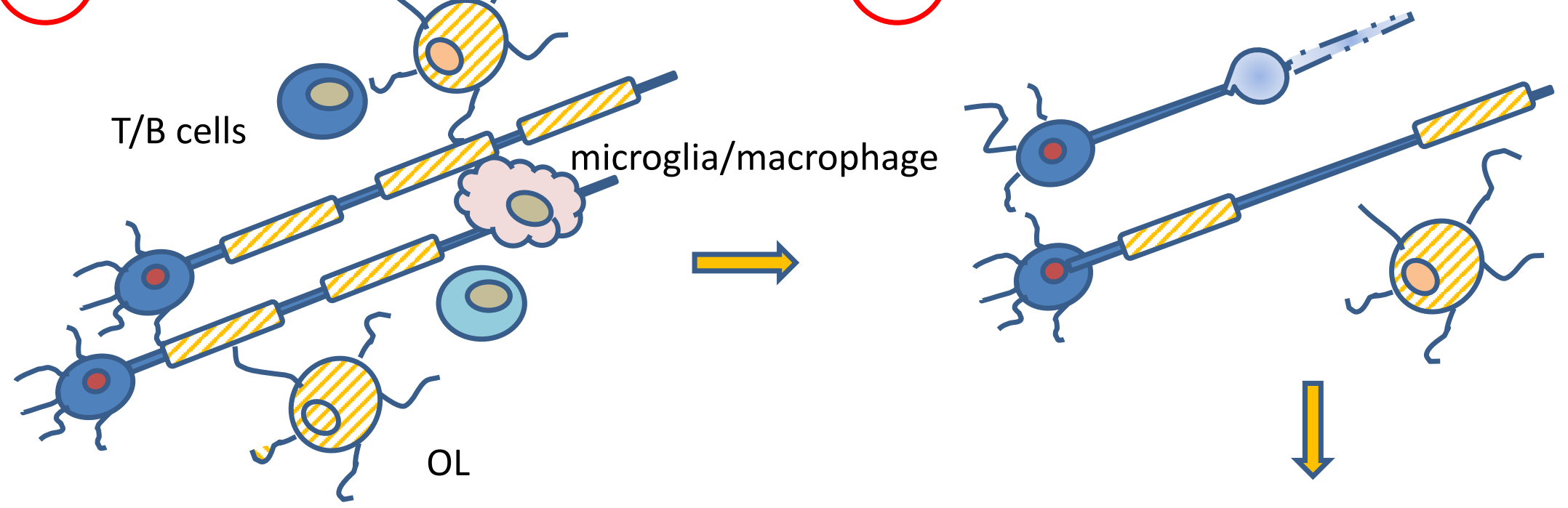

(3) Delayed axonal damage and loss

(4) To prevent disability progression

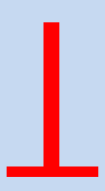

Prevent tissue damage immunotherapies
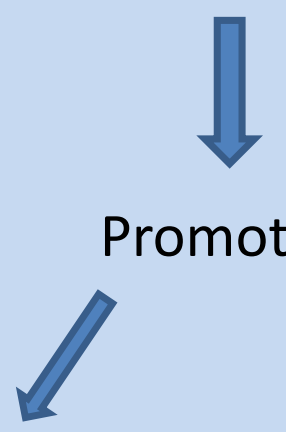

remyelination

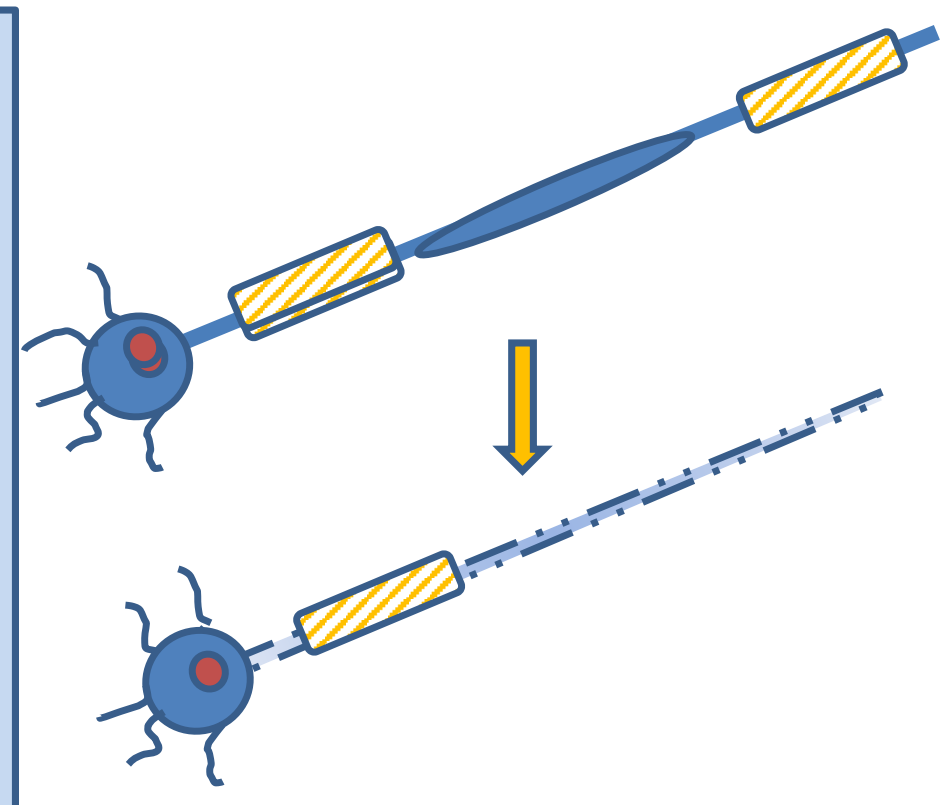



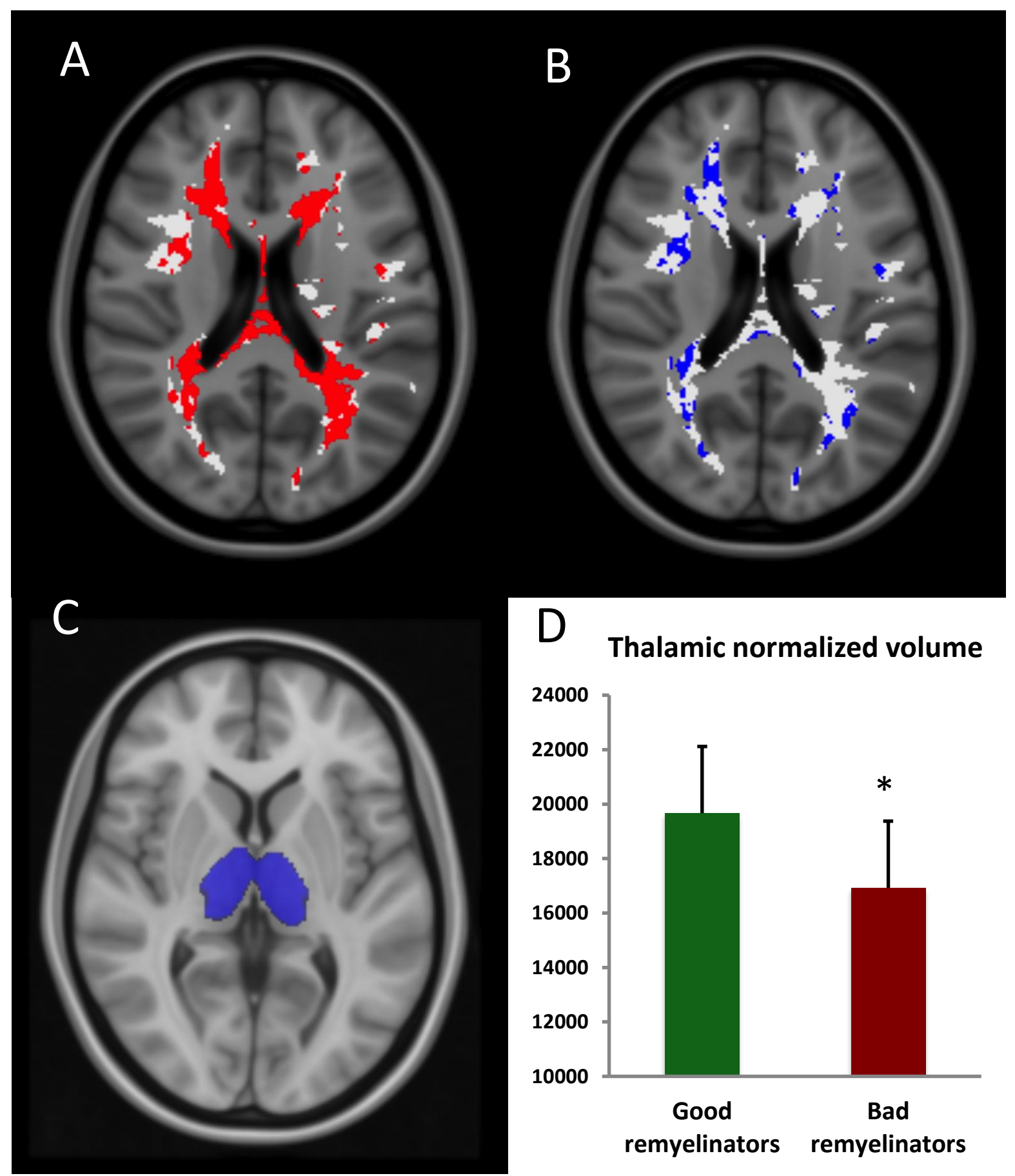

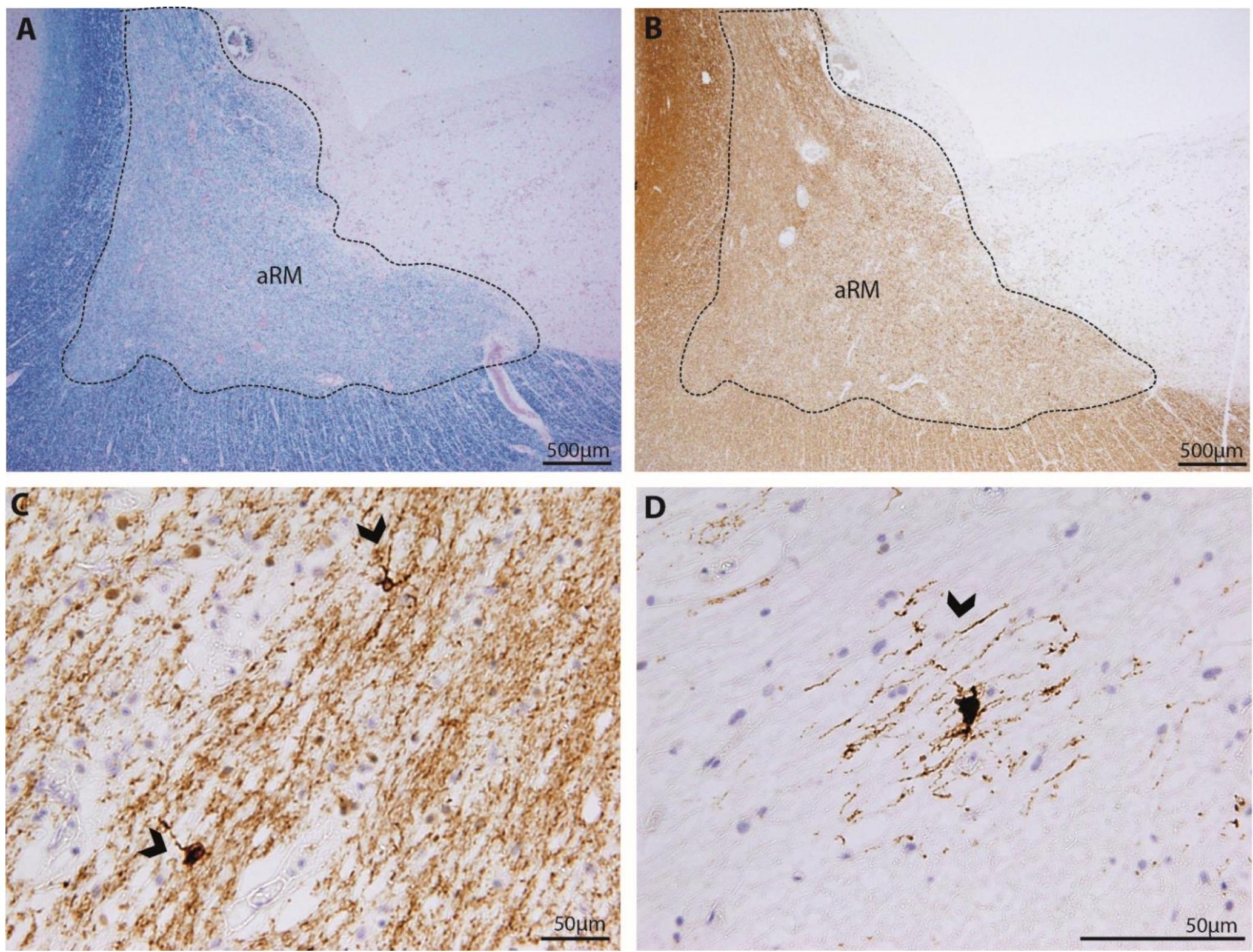


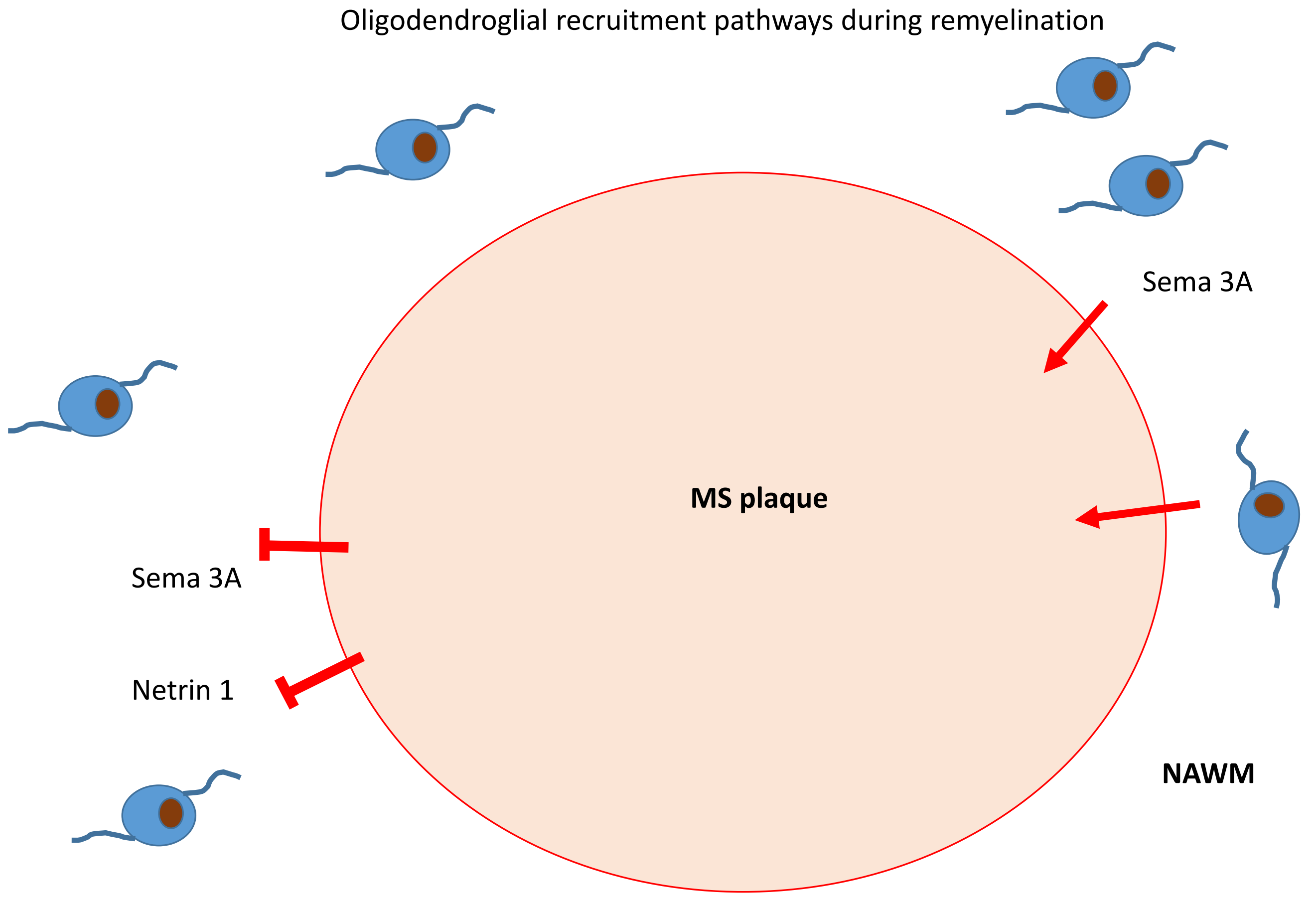


Oligodendroglial maturation pathways during remyelination
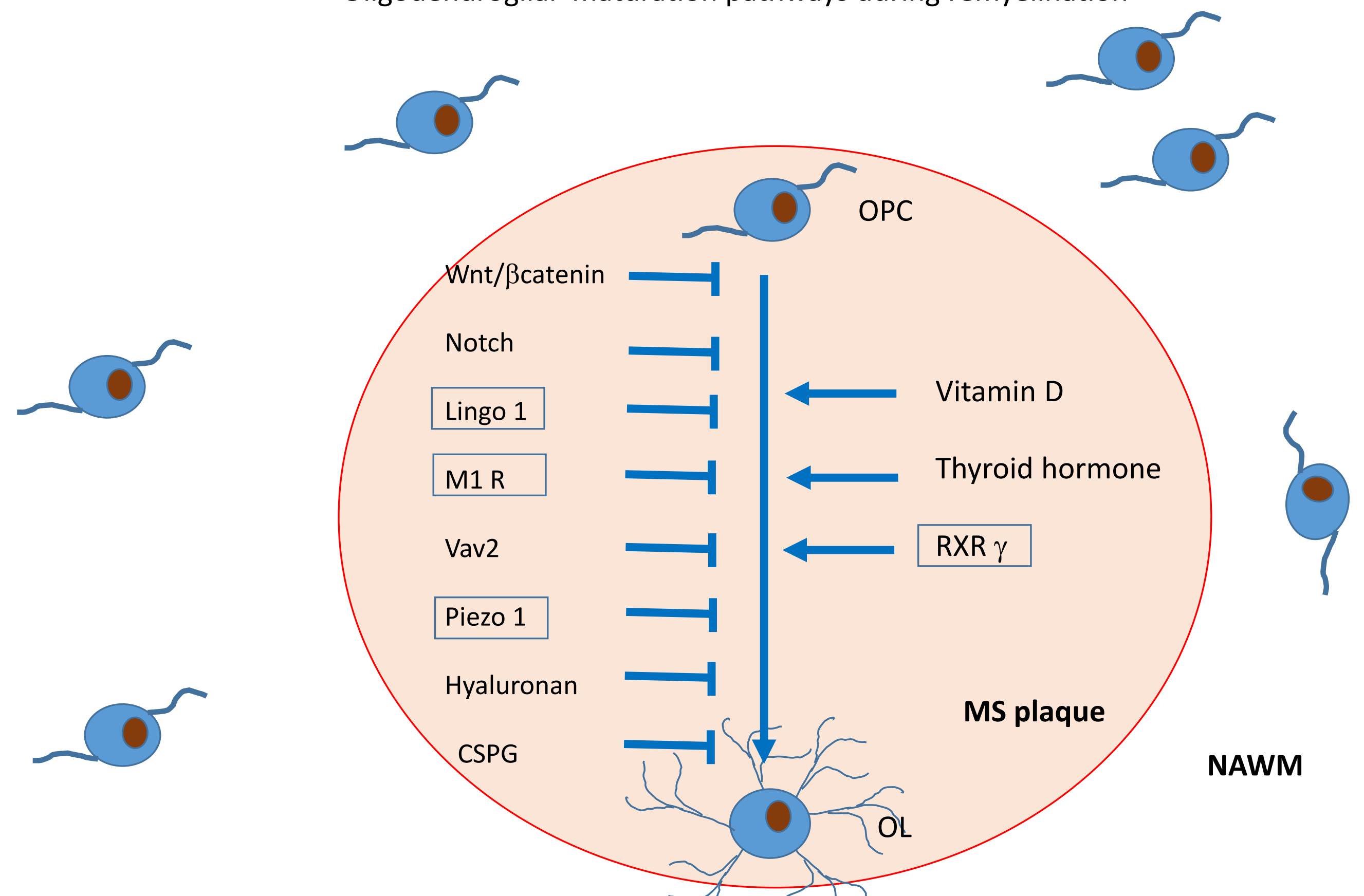


\begin{tabular}{|c|c|c|c|c|c|c|c|}
\hline Drug & Population & $\begin{array}{l}\text { Trial } \\
\text { phase }\end{array}$ & MOA & Status & $\begin{array}{l}\text { Patients } \\
\text { (ITT) }\end{array}$ & $\begin{array}{l}\text { Results/ } \\
\text { Outcome for } \\
\text { ongoing } \\
\text { study }\end{array}$ & Reference \\
\hline $\begin{array}{c}\text { GNbAC1 } \\
\text { NCT02782858 }\end{array}$ & RR-MS & 2 & $\begin{array}{c}\text { Mab against } \\
\text { HERV }\end{array}$ & completed & 270 & $\begin{array}{l}\text { Negative for } \\
\text { primary MRI } \\
\text { outcome } \\
\text { effect on MTR }\end{array}$ & Diebold 2019 \\
\hline $\begin{array}{c}\text { GSK } 239512 \\
\text { NCT01772199 }\end{array}$ & RR-MS & 2 & $\begin{array}{c}\mathrm{H}_{3} \text { receptor } \\
\text { antagonist }\end{array}$ & completed & 131 & $\begin{array}{c}\text { Small effect } \\
\text { on MTR }\end{array}$ & Schwartzbach, 2017 \\
\hline $\begin{array}{c}\text { Opicinumab } \\
\text { NCT01864148 }\end{array}$ & RMS & 2 & Anti-Lingo Mab & completed & 419 & $\begin{array}{c}\text { Negative } \\
\text { (clinical } \\
\text { outcomes) }\end{array}$ & Cadavid 2019 \\
\hline $\begin{array}{c}\text { Bexarotene } \\
\text { EudraCT 2014- } \\
003145-99\end{array}$ & RMS & 2 & $\begin{array}{c}\text { retinoid-X } \\
\text { receptor agonist }\end{array}$ & completed & 50 & pending & \\
\hline $\begin{array}{c}\text { Opicinumab } \\
\text { NCT03222973 }\end{array}$ & RMS & 2 & Anti-Lingo Mab & ongoing & & $\begin{array}{l}\text { Overall } \\
\text { Response } \\
\text { Score }\end{array}$ & \\
\hline $\begin{array}{l}\text { Domperidone } \\
\text { NCT02493049 }\end{array}$ & RMS & $\begin{array}{c}2 \\
\text { open } \\
\text { label }\end{array}$ & $\begin{array}{l}\text { Increase serum } \\
\text { prolactin }\end{array}$ & completed & 24 & $\begin{array}{l}\text { MRI measures } \\
\text { of lesion } \\
\text { repair }\end{array}$ & \\
\hline $\begin{array}{c}\text { Opicinumab } \\
\text { NCT01721161 }\end{array}$ & acute ON & 2 & Anti-Lingo Mab & completed & 82 & $\begin{array}{l}\text { reduced VEP } \\
\text { latency in PP } \\
\text { population }\end{array}$ & Cadavid 2017 \\
\hline $\begin{array}{l}\text { Clemastine } \\
\text { fumarate } \\
\text { NCT02040298 }\end{array}$ & Chronic ON & $\begin{array}{c}2 \\
\text { Cross } \\
\text { over } \\
\text { design }\end{array}$ & Anti-histaminic & completed & 50 & $\begin{array}{l}\text { reduced VEP } \\
\text { latency }\end{array}$ & Green 2017 \\
\hline $\begin{array}{l}\text { Clemastine } \\
\text { fumarate } \\
\text { NCT02521311 }\end{array}$ & Acute ON & 2 & Anti-histaminic & ongoing & & VEP latency & \\
\hline $\begin{array}{c}\text { Transorbital } \\
\text { electrical } \\
\text { stimulation } \\
\text { NCT04042363 }\end{array}$ & Acute ON & 2 & $\begin{array}{l}\text { Stimulation- } \\
\text { induced repair }\end{array}$ & & & VEP latency & \\
\hline $\begin{array}{c}\text { Transorbital } \\
\text { electrical } \\
\text { stimulation } \\
\text { NCT03862313 }\end{array}$ & Acute ON & 2 & $\begin{array}{l}\text { Stimulation- } \\
\text { induced repair }\end{array}$ & ongoing & & RNFL & \\
\hline $\begin{array}{l}\text { Nanocrystalline } \\
\text { gold } \\
\text { NCT03536559 }\end{array}$ & Chronic ON & 2 & $\begin{array}{l}\text { Myelin gene } \\
\text { transcription }\end{array}$ & ongoing & & VEP latency & \\
\hline $\begin{array}{l}\text { Bazedoxifene } \\
\text { NCT04002934 }\end{array}$ & Chronic ON & 2 & $\begin{array}{l}\text { Estrogen } \\
\text { receptor } \\
\text { modulator }\end{array}$ & ongoing & & VEP latency & \\
\hline
\end{tabular}




\begin{tabular}{l}
\hline PANEL 1 : Experimental models - roles and limitations for the study of \\
remyelination \\
\hline Current EAE (experimental auto-immune encephalomyelitis) models rely on \\
encephalitogenic T cells either induced in the animal (active) or transfused into \\
the animal (passive). Although reflecting some important features of MS \\
(inflammation and axonal loss), their usefulness for understanding \\
demyelination and remyelination is limited because demyelination and/or \\
neurodegeneration is not always seen, predicting the size and localization of \\
lesions is difficult and demyelination and remyelination can occur at the same \\
time. Some chronic EAE models have been developed but most still \\
insufficiently mimic progressive MS pathology. Viral models are complex and \\
not well adapted to study de- and remyelination. Toxin models, although \\
lacking the inflammatory component of MS, are extremely useful to unravel the \\
mechanisms of demyelination and remyelination. Cuprizone, a copper \\
chelator, induces OL apoptosis and demyelination, mostly in corpus callosum \\
and cortex, leading to robust remyelination initially, which is impaired by longer \\
exposure. Ethidium bromide induces OL and astrocyte death, with focal \\
demyelination at the site of injection, followed by extensive remyelination. \\
Lysophosphatidylcholine (LPC) damages the myelin sheaths at the site of \\
injection, followed by efficient remyelination (for details see the very \\
comprehensive review in ${ }^{17}$ )
\end{tabular}

